\title{
Derivas representacionales del cuerpo pornográfico en la cinematografía de Erika Lust
}

\author{
Representational drifts of the pornographical body in the \\ cinematography of Erika Lust
}

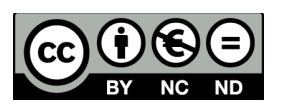

Esta obra está bajo una licencia Creative Commons Reconocimiento-No comercial-Sin Obra Derivada 
Artículo

\title{
Derivas representacionales del cuerpo pornográfico en la cinematografía de Erika Lust
}

\author{
Representational drifts of the pornographical body in the \\ cinematography of Erika Lust
}

\author{
Danna Carolina Escarpetta-Pineda ${ }^{1}$ \\ Universidad de Costa Rica \\ Costa Rica
}

Recibido: 19 de agosto de 2019 Aprobado: 09 de enero de 2020

\begin{abstract}
Resumen
La pornografía puede situarse como un dispositivo mediante el cual se construye y expone el cuerpo con la finalidad de normar prácticas y conductas de carácter social, prescribiendo la sexualidad. El presente artículo se enfoca en discutir las representaciones corporales y de la sexualidad en tres cortometrajes, cuyo posicionamiento discursivo se ha ubicado entre lo alternativo y lo postporno. Con base en dichas representaciones, se analiza hasta qué punto estos audiovisuales reproducen o no el discurso normalizador de la sexualidad androcéntrica, a partir de una comparación con las representaciones comunes en la pornografía tradicional y de la observación en la construcción de los sujetos y objetos de deseo dentro de las narrativas de cada cortometraje. Además, se generan cuestionamientos sobre si sus contenidos políticos nos permitirían hablar de la exposición de un cuerpo postpornográfico, considerando la decodificación o recodificación de la sexualidad desde el lente pornográfico y la mirada subjetiva erótica.
\end{abstract}

Palabras clave: pornografía; sexualidad; norma social; cinematografía; Erika Lust

1 Estudiante de la Unviersidad de Costa Rica. Bachiller en Antropología, por la misma universidad. ORCID: 0000-0003-4339-8728 Correo electrónico: dannaescarpetta@gmail.com

ESCENA. Revista de las artes, 2020, Vol. 80, Núm. 1, pp. 205-222 ISSN 2215-4906 


\begin{abstract}
Pornography can be placed as a device through which the body is built and exposed with the purpose of regulating social practices and behaviors, prescribing sexuality. The focus of the present article is to discuss body and sexuality representations in three short films, which have been discursively positioned between the alternative-pornographic and the post-pornographic. Based on said representations, this analysis seeks to find the extent to which these audiovisual materials reproduce the regulating discourse of androcentric sexuality, through a comparative analysis with the common representations on mainstream pornography and an observation of the construction of subjects and objects of desire. Furthermore, it enables the discussion pertaining to their political content, and if it would facilitate the exposition of a post-pornographic body, considering the decoding and recoding of sexuality through a pornographic lens, as well as the subjective-erotic gaze.
\end{abstract}

Keywords: pornography; sexuality; cinematography; social norms; Erika Lust 


\section{Aproximaciones iniciales}

Las instituciones sociales, mediante los discursos de los que se componen, han construido numerosas representaciones corporales que permean nuestras cotidianidades. Dichos discursos no son estáticos, sino que se reconstruyen a través del tiempo y del espacio según el contexto histórico en el que se sitúen. Los discursos reproducidos por tales instituciones pueden caracterizarse por un afán de normar identidades, prácticas y conductas sociales y sexuales a nivel general. Con ello, los intentos de normalización y de disciplinamiento tienen un claro impacto en los cuerpos; dado que es en el cuerpo donde se da la materialización de aquellas normas que han sido impuestas.

De esa manera, encontramos construcciones desde las instituciones hacia los cuerpos religiosos, médicos, atléticos o estéticos con sus propios patrones. A raíz de esto, se da paso a la conformación de sistemas simbólicos en términos de las representaciones de los cuerpos en las sociedades, donde, además, no puede obviarse que las normas se enuncian a través de la imposición de géneros, a partir de la sexualización del cuerpo. Así, se puede también hablar de la pornografía como un (re)productor de corporalidades normadas y de un cuerpo pornográfico que se manifiesta en la representación del acto sexual humano.

La pornografía, según Arcand (1993), se ha definido a través de lo obsceno y la censura, conceptos cuya forma ha sido dictada desde lo social y lo moral, mediante una pretensión estatal de mantener "el buen orden" y limitar los efectos supuestamente negativos de las imágenes pornográficas dentro de la sociedad. El significado de lo obsceno se construye dentro del contexto histórico y sociocultural que lo enmarca. Sin embargo, en un sentido más amplio, la exposición sexualizada, abierta y cruda del cuerpo es un elemento transversal a las diferentes conceptualizaciones de lo obsceno. Dicha exposición del cuerpo constituye, en principio, la imagen pornográfica. De este modo, la pornografía, al igual que lo obsceno, se configura entre la producción y el consumo de la imagen situados a partir de la mirada de los sujetos involucrados en dicho proceso.

Para Ercole Lissardi (2013) el cuerpo pornográfico es "un cuerpo humano abierto, expuesto a la mirada en sus orificios, pliegues o protuberancias, dispuesto al coito sexual” (p. 115), y se conforma como un constructo cultural estimulador de la concupiscencia. Asimismo, el autor señala que, debido a la sobreabundancia de representaciones pornográficas, el cuerpo pornográfico se percibe como un cuerpo abstracto, sin atributos particulares, en el sentido de que este cuerpo permite también la intersección entre los cuerpos que ofrecen la fábrica de la pornografía y los cuerpos que desea el individuo. A raíz de esto, se conforma la idea de que el cuerpo deseado es único y concreto, mientras que el pornográfico es anónimo (p. 110). Por ello, la estimulación que provoca el cuerpo pornográfico no está dirigida hacia alguien en particular. 
La reproducción de normas y corporalidades que se realiza desde la pornografía ha tomado elementos transversales de los discursos de las instituciones sociales. Uno de los elementos en común que se puede encontrar es el del modelo androcéntrico de sexualidad que, como apunta Rachel Maines (2001), ha sido ampliamente construido y difundido desde el discurso médico occidental. Este modelo androcéntrico de sexualidad se compone de tres pasos esenciales, a saber: estimulación, penetración y orgasmo masculino. Se espera que el orgasmo femenino ocurra por medio de la penetración vaginal $-y$ secundando el orgasmo masculino - pero si este no ocurre, y con base en dicho modelo sexual, el sexo no pierde su legitimidad como tal. De manera que, el orgasmo femenino queda excluido de esta fórmula, por lo que resulta, de acuerdo con este paradigma, invisibilizado de la experiencia sexual de las mujeres. Esta problemática responde a un sesgo androcéntrico que se reproduce con suma frecuencia en las producciones de la pornoindustria.

Como todo dispositivo y discurso social, la pornografía también se transforma y adapta a su contexto y necesidades; de allí que hayan surgido diversos subgéneros. Entre estos se pueden citar, el subgénero amateur, caracterizado por ser una filmación casera y por la ausencia de participantes profesionales. También, existe el "gonzo" que, con influencia de lo amateur, busca plasmar representaciones realistas por medio del uso de tomas sin corte, planos subjetivos y primeros planos, con lo que hace del espectador el protagonista; además, en esa búsqueda por lo real, se ha caracterizado por incluir prácticas sexuales extremas. Asimismo, se encuentra el subgénero alternativo, el cual, según señala Fabián Giménez (2015), retratará los intentos de las representaciones corporales, del deseo y del placer de desmarcarse de las tendencias dominantes en la pornografía tradicional, cuyas representaciones se basan en el discurso hegemónico y misógino que caracteriza a otros subgéneros, como el "gonzo". Así, la pornografía alternativa se plantea como women-friend$l y$, en tanto busca una ruptura con las representaciones misóginas y explotadoras y, por ende, ensaya un reencuentro basado en un discurso de empoderamiento femenino donde las expresiones subjetivas de lo erótico tienen lugar dentro de la industria.

La pornografía alternativa, siguiendo la línea de Giménez (2015), se plantea como disidente frente a la pornografía tradicional. Sin embargo, sus principales rupturas se manifiestan con respecto a la estética. Este factor, entonces, aboga un cambio tanto en términos de fotografía, como en términos de los significantes asignados a lo alternativo, los cuales se representan por medio de los cuerpos. Aun así, la pornografía alternativa se podría comprender como una continuidad con los demás subgéneros, siempre y cuando la conceptualización de obscenidad, placer y goce no se deconstruya.

La postpornografía, por otro lado, busca problematizar esos conceptos que la pornografía alternativa no logra deconstruir, para así transgredir las representaciones corpora- 
les y de placer que han sido normalizadas y reproducidas desde el dispositivo pornográfico. Así como lo expresa María Llopis (2010), en el postporno se analiza críticamente el origen del deseo y de las fantasías sexuales, por lo que resulta imprescindible cuestionar a la industria pornográfica y las representaciones de sexualidad que reproducen.

Dicho esto, en el presente artículo me propongo analizar cómo se nos presenta el cuerpo pornográfico - y los elementos que lo conforman en términos de prácticas - en cortos cinematográficos que se posicionan discursivamente entre la pornografía alternativa y la postpornografía; en su intento por distanciarse de la pornografía tradicional basada en el modelo androcéntrico de sexualidad. Para esto, tomo como punto de partida el proyecto XConfessions de Erika Lust, el cual consiste en la producción de cortometrajes pornográficos con base en confesiones eróticas anónimas enviadas por sus suscriptores. El primer volumen de cortometrajes de este proyecto fue lanzado en el 2013 y desde entonces se ha mantenido en vigencia; por lo tanto, debido a la amplitud de producciones bajo dicho proyecto, me basaré específicamente en el volumen siete de XConfessions de Erika Lust (2016).

Si bien la pornografía de Erika Lust ha sido catalogada críticamente como pornografía para mujeres más que como postpornografía - debido al contenido político por el cual aboga el postporno - , el volumen seleccionado cuenta con cortos que han sido producidos por Lust, pero dirigidos por artistas que se han acercado a lo alternativo y a lo postporno. De ahí que, en adelante, me ocuparé de tres cortos de dicho volumen (The Bitchhiker, dirigido por Olympe de G.; Female Ejaculation, por Paulita Pappel y Horny Beasts por Erika Lust) con el objetivo de estudiar hasta qué punto estos audiovisuales reproducen o no el discurso normalizador de la sexualidad androcéntrica.

La selección de las tres directoras consiste en el diverso acercamiento que han tenido en torno a la pornografía y el posicionamiento político sobre el mismo, lo que permite vislumbrar elementos que se atribuyen a la producción de pornografía alternativa o postpornográfica. Para Olympe de G., pornógrafa amateur y feminista, su proyecto se ha basado en hacer de la pornografía un lugar para la inclusividad y diversidad de sexualidades y cuerpos, a modo de romper con la estandarización. Para ella, estandarizar las prácticas sexuales las convierte en mandatos (Bonte, 18 de septiembre de 2018). Con esto, ha dado pie a la producción de cortos pornográficos alternativos así como contenido erótico auditivo, con el cual busca explorar la estimulación erótica por medio de otros sentidos.

Paulita Pappel, pornógrafa feminista, ha declarado en entrevistas que la intención de su trabajo es hacer de la industria pornográfica un lugar más auténtico para las mujeres, donde no se genere impacto negativo (Corner, 25 de mayo de 2018). Asimismo, creó un proyecto y plataforma llamado Lustery en el que sus suscriptores envían porno casero con sus parejas pero, generalmente, desde la mirada de las mujeres, lo que muestra otras perspectivas de 
corporalidades y deseos. Sin embargo, cabe recalcar que la pornógrafa señaló en su entrevista no tener problema con la pornografía mainstream y que incluso considera problemático diferenciarla de la feminista, al darle un valor negativo a la primera. Por ello, es de interés observar cómo se presenta su trabajo y su representación de la sexualidad en el marco de una propuesta XConfessions, que discursivamente se ha posicionado como alternativa.

En cuanto a Erika Lust, ella ha denominado su producción como pornografía para mujeres, en la que busca que se hable de la sexualidad de las mujeres, donde ellas sean las portadoras de la mirada y así resignificar al objeto de deseo, puesto que la narrativa es construida por ellas. Es así que también define su producción pornográfica como feminista, pues considera que, como toda expresión artística y cultural, la pornografía posee un discurso que puede ser abordado desde el feminismo (Lust, 2008). Además, se aboga por una estética más trabajada en la que se seleccionan con detalle la música, las luces y los accesorios en general. Como señala Lust (2008), estos elementos son fundamentales para ella y para el público al cual va dirigida su producción, puesto que son poblaciones cuya mirada y deseo no han sido representados en la pornografía tradicional. De tal forma, es llamativo explorar cómo se muestra esa mirada femenina y la resignificación del deseo en sus trabajos tanto como productora como directora.

\section{Bitchhiker}

El corto Bitchhiker, dirigido por Olympe de G. (2016), abre con el siguiente texto: "I always wanted a man to be man enough to ride behind me. Let himself go. And let me take him [Siempre quise un hombre sea suficientemente hombre para que me monte por detrás. Que se deje ir. Y que me deje tomarlo.....]" (Olympe de G., 2016, 25:31) En seguida, se muestra a una mujer con prendas de cuero conduciendo una motocicleta estilo pandillera. Al encontrarse a un hombre solitario sobre la carretera, decide hacerle un aventón, no sin antes indicarle que se desvista. Seguidamente, se dirigen hacia lo que parece un taller mecánico abandonado. Esos primeros minutos se caracterizan por tomas dirigidas hacia el cuerpo del hombre, desde sus genitales hasta el torso y los brazos. En cuanto a sus cuerpos, ambos lucen esbeltos, de tez clara y cabello corto. La mujer, por su parte, tiene tatuajes en los brazos.

Al llegar al lugar, el hombre suelta su bolso y la cámara dirige su enfoque hacia sus pertenencias: un dildo con arnés que se sujeta a modo de cinturón, conocido comúnmente como strap-on, un vibrador y aceite de motor, objetos que serán imprescindibles en la trama. El aceite de motor se usa como lubricante en el momento en el cual el hombre penetra a la mujer, no existen tomas previas de sexo oral de parte de ninguno. A medida en que se dan los movimientos corporales durante la penetración, el aceite se va esparciendo en los dos cuerpos.

ESCENA. Revista de las artes, 2020, Vol. 80, Núm. 1 (julio-diciembre), pp. 205-222 
El aceite no es utilizado únicamente para lubricar los genitales, sino que ambos personajes toman de este y se van llenando alrededor de sus cuerpos por lo que empiezan a verse extensamente embarrados. Más adelante se da el empleo del vibrador y del strapon. El uso del vibrador se dirige hacia el placer de la mujer y durante estas escenas las tomas capturan únicamente los senos y cara de la mujer con unas breves tomas de la barbilla y los pezones del hombre. De manera que no se presentan tomas enfocadas en los genitales de ninguno de los dos. Cuando va el turno del strap-on, la mujer penetra al hombre, estando él sobre ella y de espaldas. Las tomas en este momento van totalmente dirigidas hacia el cuerpo del hombre. Esta escena concluye con el medical shot -nombre que se le ha dado en la pornografía a los planos detalle de los genitales -, donde se enfoca directo al pene y su eyaculación, la cual cae al suelo y no sobre el cuerpo de la mujer.

Cuando se toman como referencia las categorías BDSM o Dominatrix de la pornografía tradicional, podemos encontrar elementos en común relacionados a los juguetes sexuales y a las prendas usadas por los intérpretes. Además, en la pornografía son aún más marcados lo roles de dominación-sumisión que se ejercen y suelen ser estáticos a lo largo de los filmes. En las representaciones de los juguetes sexuales se muestra cómo la persona que dispone y manipula los elementos en cuestión es colocada en una posición de dominación sobre el otro, al decidir qué movimientos ejecutar, así como la velocidad e intensidad que busca conseguir. En Bitchhiker, llama la atención cómo los roles se intercambian sin generar una ruptura brusca en el ambiente pornográfico. El penetrar y/o ser penetrado no se restringe a esencialismos ni normativas sexuales. Inventarse un cuerpo erótico extenso deviene una posibilidad bien enmarcada en este corto, a través de instrumentos como el strap-on, el vibrador y el aceite de motor. Las prácticas y cuerpos van más allá de los estereotipos de conductas femeninas y masculinas.

Se pueden distinguir elementos que significan una cercanía a lo postpornográfico, entre otros, el dinamismo entre roles, la experimentación con artefactos a los cuales, no se les ha asignado un carácter erótico desde el punto de vista de las sexualidades normativas y la bidireccionalidad del deseo. La fotografía toma distancia del sesgo androcéntrico. Mientras que se expresan como erógenas partes del cuerpo que no han sido inscritas desde el entendido de placer y erotismo corporal que muestra la imagen pornográfica convencional. Asimismo, se expresa un rompimiento del modelo sexual que se enuncia con la ausencia del sexo oral, pues este es uno de los elementos que forma parte de la codificación del acto sexual.

A su vez, se presenta un elemento clave y disruptivo respecto a la mirada androcéntrica en la pornografía. Laura Mulvey (1999) ha problematizado cómo la narrativa fímica ha encajado con las ideologías dominantes que han ordenado cuáles son los cuerpos que miran y desean - activos - y cuáles son los mirados y deseados - pasivos-. Así, la figura 
masculina no puede llevar la carga de la cosificación sexual, sino que su rol es activo; es quien propicia que la historia suceda y es quien la controla. Por esto, las mujeres quedan relegadas a ser el objeto erótico y de deseo para los personajes de la historia y para los espectadores de los filmes, puesto que, cuando las narrativas se construyen desde la mirada masculina se dicta hacia quiénes están dirigidas las producciones fímicas, es decir, el protagonista masculino es el portador de la mirada del espectador (p. 838).

En Bitchhiker, se denota la búsqueda por romper con ese sesgo en la mirada y la reproducción de los roles entre quiénes son el sujeto y el objeto de deseo. Esta ruptura se manifiesta por medio de las diversas tomas de la cámara que eran enfocadas en el cuerpo del hombre - principalmente cuando fue penetrado por la mujer - con lo que se propone que el hombre pueda actuar para el deseo de las mujeres. Así, se apuntó a la recodificación entre sujetos y objetos de deseo, donde la mirada y el deseo de las mujeres podía coincidir con las imágenes capturadas a través del lente pornográfico; el lente convierte al hombre en el objeto de deseo, siendo la figura femenina la portadora de la mirada.

\section{Female Ejaculation}

En Female Ejaculation, dirigido por Paulita Pappel (2016), se muestra una reunión entre amigos hombres y mujeres, en la cual hablan sobre la eyaculación femenina. Una pareja de hombres manifiesta no saber que las mujeres eyaculan y una mujer dice que ella aprendió por sí misma a hacerlo. En privado, uno de los hombres le dice a ella "I would like you to come in my face [Me gustaría que te vinieras en mi cara]" (Pappel, 2016, 1:33:44) y con esto se da paso al nudo erótico del clip. Algunos de los elementos que sobresalen son la presencia de vello en el cuerpo de ambos - tanto en genitales como en axilas y piernas-, la presencia de tatuajes y piercings y el hecho de que la mujer aparenta una edad mayor que la del hombre. A diferencia del corto anterior, y de todos los otros clips del volumen, es el único en el cual los personajes usan condón.

Se muestran tomas más directas hacia los genitales, tanto cuando se da la penetración como cuando toma lugar el sexo oral. En este corto, a diferencia de The Bitchhiker, el orgasmo y la eyaculación masculina suceden primero. Aquí, él se retira el condón y eyacula sobre el abdomen femenino, en seguida ella dice "I didn't know men can ejaculate too" [No sabía que los hombres también pueden eyacular] (Pappel, 2016, 1:41:09) a modo de sarcasmo, por la conversación que tuvieron antes, en la que un hombre se preguntó si la eyaculación femenina existía. Una vez dado dicho diálogo entre ambos, comienza la estimulación hacia la mujer, en la cual ella manipula un vibrador y él la penetra con sus dedos. De esa forma, el acto sexual concluye con la eyaculación femenina mostrándose en plano detalle o medical shot.

ESCENA. Revista de las artes, 2020, Vol. 80, Núm. 1 (julio-diciembre), pp. 205-222 
Uno de los aspectos a señalar sobre el corto es la aparición del money shot, es decir, la eyaculación sobre el cuerpo de las mujeres. Para los pornógrafos, alcanzar esta toma es un logro, pues se ha considerado la representación más verosímil del coito debido a que es la expresión visual con mayor uso para representar un orgasmo y con la que suelen concluir los filmes pornográficos. El cum shot o money shot se ha caracterizado por una representación del ejercicio de poder del hombre sobre la mujer, entendiéndolo como una entrega unilateral del placer donde la mujer está a disposición del deseo del otro (Romera, 2016). Ante la dificultad de los directores y actores de conseguir retratar de forma verosímil el orgasmo femenino, este se reduce a gemidos y a una actuación donde pareciera que la mujer alcanza su orgasmo cuando el hombre ha eyaculado.

En relación con la búsqueda de porno con eyaculación femenina, en los sitios de pornografía tradicional, me interesa señalar algunos elementos diferenciales en el corto que me encuentro analizando. Primero, a la categoría se le llama comúnmente squirt, que significa "chorro", por lo que, al teatralizar la eyaculación femenina se muestran literalmente chorros. Este es un primer contraste con este corto, pues la eyaculación es más corta y en menor cantidad. En segundo lugar, la textura del fluido eyaculado, cuando se busca retratar como chorro, coincide con lo mostrado en Female Ejaculation y con las categorías de squirt en los sitios web de porno. Sin embargo, otros videos que llevan como nombre female ejaculation o female orgasm ejaculation, muestran líquidos con texturas lechosas. Esto bien podría ocurrir por intentos de asemejar el color de la eyaculación femenina con la masculina o bien para marcar una pauta donde el observador no contemple que podría ser orina lo que la actriz está expulsando, líquido comprendido como un desecho humano -abyecto, en palabras de Kristeva (1988) - y que por ende no debería ser objeto de excitación.

A lo largo de la historia, el orgasmo femenino ha sido invisibilizado y dejado en manos de los hombres, ya sea un doctor o un esposo, cuando a las mujeres les diagnosticaban histeria (Maines, 2001). De allí viene, en gran parte, el porqué el discurso médico permea lo que se ha entendido como normalización de la sexualidad, pues eran justamente los doctores, como apunta Maines (2001), quienes le enseñaban a los esposos - de aquellas mujeres diagnosticadas con histeria - cómo estimular el clítoris y que, además, este debía ser estimulado antes del acto sexual. De ese modo, se reforzaba la codificación de la sexualidad y se relegaba a las mujeres de su autonomía y conocimiento sobre sus propios cuerpos.

La apuesta del corto, en ese sentido, es plasmar esa entrega del placer no como algo unilateral, sino como algo que sucede en dos sentidos. El orgasmo no ocurre, por tanto, como en los filmes pornográficos tradicionales donde se da una suerte de sincronización. En Female Ejaculation, el personaje femenino no se muestra como el otro pasivo en térmi- 
nos de la obtención del placer. El placer no se le coloca como algo ajeno e incompatible, sino que va hacia él, manipula por sí misma el vibrador y da instrucciones, pide lo que quiere que le hagan y cómo lo quiere, su objetivo era eyacular y no pensaba desistir hasta conseguirlo.

En consecuencia, se pueden ver plasmadas en el corto algunas rupturas respecto a la pornografía tradicional, como la representación de corporalidades no convencionales, y que la mujer dirigiera el acto sexual como tal. Además de ello, no se expresa un sesgo androcéntrico reproducido en la fotografía. Sin embargo, a partir de las categorías conceptuales discutidas anteriormente, el corto se encuentra dentro del subgénero alternativo en tanto la concepción de placer y goce parten de un lugar ya codificado y, por ende, normalizado - en el marco del modelo androcéntrico de sexualidad-sobre cómo exponer el cuerpo y cómo usarlo en el desenvolvimiento sexual. Es decir, se inscribe en un terreno políticamente correcto por lo que no toma una distancia significativa respecto de la pornografía tradicional.

\section{Horny Beasts}

Este último filme fue dirigido por Erika Lust en el 2016 y se seleccionó para responder a un afán por analizar el enfoque de esta autora propiamente como directora y el porqué su trabajo se ha catalogado como pornografía para mujeres. El audiovisual se caracteriza por la danza y comienza con un acto performativo, donde cinco hombres sin camisas, con bozales y orejas, simulando ser canes, acechan a una mujer que se encontraba sola en lo que parecieran ser bodegas. Los hombres/canes rodean a la mujer, bailan a su alrededor, la olfatean y realizan movimientos corporales que muestran imposición sobre su cuerpo. En el momento en el que la mujer trata de huir de en medio de ellos, le cierran las posibles salidas, uniendo sus cuerpos masculinos. Cuando finalmente logra huir es perseguida, hasta que termina uniéndose a la danza y, entre movimientos, ellos se muestran a disposición de ella, se mueven según esta.

La primera parte transcurre con una estética gang bang - un tipo orgía en la que participa una mujer o un hombre pasivo y tres o más hombres que toman roles activos-, entre música, movimientos sincronizados y tomas fortuitas del acto sexual en sí. La segunda va de lleno al coito, pero solamente entre ella y dos de los hombres. Los bozales de los personajes marcaban una barrera de contacto, no hacían uso de sus bocas en absoluto, el contacto hacia ella se limitaba a sus manos y a sus penes, no había intercambio alguno entre ellos. Las posiciones en el coito mantenían la imposición masculina hacia ella, entre jalones de cabello, ahorcadas, nalgadas y arcadas.

Por un lado, los cuerpos masculinos son esbeltos y musculosos, con un predominante enfoque hacia brazos y penes anchos, que se mantienen erectos simbolizando la masculinidad. Ella, por otro lado, se queda diminuta al lado de ellos, retratando docilidad.

ESCENA. Revista de las artes, 2020, Vol. 80, Núm. 1 (julio-diciembre), pp. 205-222 
El acto sexual concluye con el orgasmo masculino, para lo cual acuestan a la mujer boca arriba y se masturban sobre ella hasta eyacular en su pecho. Es decir, nos coloca frente al cum shot propio de la pornografía tradicional.

Acá resultan explícitos los códigos dominantes con referencia a lo que se entiende como bello y deseable. Los cuerpos responden al imaginario heterosexual, que ya ha sido vastamente representado en la pornografía tradicional y los discursos corporales médicos, deportivos y estéticos, en general, los cuales han definido los parámetros de belleza femenina y masculina. Si bien la actriz en cuestión no es voluptuosa como suele retratarse en dichos discursos normalizantes del cuerpo, sigue contando con características como la delgadez, ser blanca y tener el cabello largo - aspectos que han sido integrados dentro de la feminidad - . Para Guerrero (2014) los personajes feministas que Erika Lust busca retratar corresponden a la fantasía heteropatriarcal que basa su presunto empoderamiento en una aparente igualdad con el hombre bello, blanco y consumidor.

Además de estos patrones dominantes, se encuentra el uso del money shot que, como señalé con respecto al corto Female Ejaculation, simboliza el ejercicio de poder masculino, más claramente marcado en este corto. En efecto, el acto sexual concluye con la eyaculación masculina, en una posición corporal en la cual se denota la jerarquía entre los cuerpos de los hombres y el de la mujer. Aunado a ello, en ninguna toma se aprecia que la mujer haya alcanzado el orgasmo, pues en los filmes pornográficos donde no muestran eyaculación femenina como tal, se recurre a otros elementos corporales como gemidos y relajación del cuerpo. Desde lo observado, el cum shot o money shot, según Romera (2016), "se establece como la demostración del clímax sexual masculino y refuerza la idea aristotélica de la mujer incompleta, castrada y despojada del poder fálico” (p. 211).

\section{Cuerpos e interpretaciones: ¿de lo hegemónico a lo subversivo?}

La postpornografía, más allá de la búsqueda por nuevas representaciones en la pornografía, aboga por el empoderamiento y agenciamiento erótico que permita a las personas reapropiarse de las representaciones sexuales en estos productos. Por ello, su cobijo teórico se halla en el feminismo, lo queer y lo crip, tal y como lo argumenta Roberto Echavarren (2009):

El postporno enfatiza la mayor tolerancia hacia los tipos de cuerpo alternativas y las identificaciones diferenciales, visiones de sexo y activismo punk. En la web, grupos minoritarios, postfeministas, queers y minorías étnicas usan el porno como una contribución a sus redes sociales. Así establecen una posición contra las industrias que han producido el porno hasta hoy. (p. 72) 
Preciado, por su parte, puntualiza que:

El movimiento postporno es el proceso de devenir sujeto de aquellos cuerpos que hasta ahora solo habían podido ser objetos abyectos de la representación pornográfica: las mujeres, las minorías sexuales, los cuerpos no-blancos, los transexuales, intersexuales y transgénero, los cuerpos deformes o discapacitados. (2012, párr. 22)

El contenido político ha sido la principal base de la propuesta postpornográfica y es lo que le ha dado lugar en espacios críticos de producción. Además, esta propuesta generalmente es autogestionada, lo que da lugar a la reapropiación de las representaciones del erotismo, en esa unión entre lo corporal y las prácticas sexuales, cuyo lugar está fuera de lo que se ha normado a través de los discursos.

Si bien las producciones de Erika Lust se han catalogado, en ocasiones, entre lo posporno y lo alternativo, estas también han sido recurrentemente catalogadas por la misma productora como porno para mujeres (Lust, 2008). Esta directora y productora se caracteriza por la inserción de patrones estéticos, dándole importancia a elementos como la luz, la fotografía y el vestuario, así como a una línea argumentativa dentro de los filmes; es decir, nos da una historia. Para ella, sus producciones son feministas en tanto se busca una ruptura con los clichés y relaciones sexistas propias de la pornografía tradicional, con lo que da paso a la representación de las mujeres como sujetos activos y de deseo. Sin embargo, en ese afán por una estética e historia, hay una falta de cuestionamiento sobre otros elementos simbólicos que forman parte de la producción. Por ejemplo, las representaciones del money shot se pueden encontrar similares a lo que se observa en la pornografía tradicional, en cuanto a las posiciones jerárquicas hombre-mujer y al uso del semen, especialmente, respecto al corto Horny Beasts y alejándose más en The Bitchhiker. No obstante, cabe recordar que este último no es dirigido por Erika Lust.

En su libro, Porno para mujeres (2008), Erika Lust aborda el porno poco realista que han hecho los hombres históricamente y ofrece una lista de los clichés de esas producciones, al señalar algunos como "los hombres siempre sacan su polla antes de correrse" (p. 28) y "las mujeres sonríen y disfrutan cuando los hombres las ahogan con su polla" (p. 26). Sin embargo, del análisis de Horny Beasts o incluso de Female Ejaculation se entiende que, de igual forma, esas prácticas están presentes en estas propuestas en principio alternativas.

Las corporalidades que se muestran en este volumen responden, en síntesis, a las representaciones hegemónicas de los discursos normalizantes. Las y los protagonistas son mujeres blancas, altas y delgadas; hombres musculosos y blancos, que calzan dentro de lo heteronormativo y dentro de aquellos cuerpos que son aptos para tener disfrute sexual acti-

ESCENA. Revista de las artes, 2020, Vol. 80, Núm. 1 (julio-diciembre), pp. 205-222 
vo; no son gordos, negros, viejos, trans o discapacitados. En otras palabras, esos cuerpos abyectos, como diría Preciado siguiendo a Kristeva (2012), no encuentran lugar dentro de la producción porno que acá he analizado. Aunado a ello, vemos cómo se valida repetidamente la codificación sexual, a modo de manual, del modelo androcéntrico de sexualidad respecto al acto sexual: sexo oral, penetración y eyaculación externa (orgasmo masculino), en el mismo orden de la pornografía mainstream.

Vale enfatizar en que nos encontramos ante una producción donde el discurso de inclusión tiene alcances limitados, en la medida en que apunta a una clase social con sed de normalidad. Si además partimos de que su producción tampoco es inclusiva en términos de quiénes pueden acceder a este material - ya que no es gratuito - , se puede hablar, en palabras de Bourdieu (1979), de un gusto configurado por condiciones sociales como el capital económico y el capital cultural. De manera que Lust Films produce un cuerpo pornográfico destinado al consumo de un cuerpo social de clase media-alta, normado por los discursos de las instituciones que modelan y norman al cuerpo respecto a las prácticas pertenecientes a dicha clase. Claro está que encontramos algunas excepciones en la pornografía distribuida por la compañía de Lust, pero, como señalé antes, resulta notorio que ello ocurre, en el escenario del presente análisis, cuando quienes dirigen estos cortos son personas que han tenido cierta trayectoria trabajando con pornografía alterna, a pesar de darle paso a producciones alternas en Lust Films. En fin, encuentro que los colectivos históricamente excluidos del imaginario sexual siguen sin encontrar su lugar en la pornografía aquí analizada.

\section{Decodificar la normatividad}

Ante la multitud de reacciones frente a una sexualidad normalizada, a través de las formas de disciplinamiento corporal que ejecutan las diversas instituciones sociales -ya sea por medio de control social formal o informal- han surgido formas de respuesta que, como lo he mencionado, han buscado hacerse un cuerpo reapropiado y representarlo a partir de medios alternos. El norte es la apertura de un espacio para el agenciamiento propio sobre las prácticas y corporalidades de sectores excluidos de los circuitos sexuales "normales"; en el marco del avance en las tecnologías y la utilización masiva de Internet, donde se lograr adquirir un tipo de agencia pornográfica en el que cada persona tiene algún potencial como pornógrafa.

A través de estos medios se han retratado nuevas formas de placer y deseo; más bien, formas ocultas: aquellas que no se permitían documentar mediante el lente de una cámara por catalogarse como inmorales o abyectas, en fin, por salirse de las barreras de lo considerado normal y correcto según el orden social. Se plantea cuestionar cómo se 
utiliza el cuerpo mediante un proceso de decodificación donde la relación entre placer y deseo no sea unívoca en referencia a dicho discurso normalizador. Con esto, la propuesta postpornográfica de desvincular el deseo del placer normado. En palabras de Peralta (2017):

son múltiples[;] las potencias que despliega el posporno al originar producciones artístico-políticas que desafían los modos de comprender, producir y consumir imágenes y discursos relativos a la sexualidad, así como sugiere y promueve prácticas sexuales que se alejan deliberadamente de los patrones impuestos por el sistema patriarcal y heterosexista. [La asociación de la usina] con el dominio pospornográfico implica una producción regida por una lógica plástica antes que mecánica, en la que los cuerpos descubren y exploran articulaciones de placer y posibilidades subjetivas más allá de los binarismos que la pornografía tradicional se empeña en reproducir y mantener. (p. 185)

Sin embargo, persiste la pregunta de cómo lograr la desvinculación de estos patrones impuestos desde un sistema binario y heterosexista, sin caer en procesos en los que se genera una recodificación del cuerpo y la sexualidad. ¿Cómo trascender, pues, la mera substitución de una antigua normatividad por una nueva normatividad? Si bien desde algunas corrientes posporno se establece como consigna el ser políticamente incorrecto e incluso se incurre en clasificar cuáles corrientes cumplen con dicho patrón, es de cuestionar hasta dónde podría llegar la decodificación de la sexualidad.

Al respecto, Alejandro Pineda (2005) señala que el problema surge cuando en una determinada teatralización se da la repetición continuada de gestos. Así, la reiteración que en una primera instancia parece resultar subversiva y transgresora, al devenir hábito, termina ratificándose, dándose por natural (p. 188). Esta repetición de gestos y actos deriva de establecer normas sobre cómo usar el cuerpo, que se sitúan también dentro de lo que Bourdieu teoriza en torno al habitus. Por lo que, ante esos modos que se instalan como sistemáticos cabe preguntarse si logran seguir considerándose subversivos, cuando hay una estructura que los respalda discursivamente. Esto resulta prometedor al encontrarnos en un contexto que ha propiciado el auge de sitios pornográficos con categorías inimaginables, donde se busca retratar pluralidades de miradas, sujetos y objetos de deseo para la singularidad de cada espectador. Si la pornografía alternativa posee realmente la capacidad para que, a partir de agenciamientos corporales retratados en un filme, se logre llegar a rupturas a nivel más material, la pregunta radica en qué cuerpo(s) pornográfico(s) se están construyendo y cómo se (des)vinculan e interactúan con los discursos dominantes y normalizantes de las instituciones sociales.

ESCENA. Revista de las artes, 2020, Vol. 80, Núm. 1 (julio-diciembre), pp. 205-222 
Derivas representacionales del cuerpo pornográfico en la cinematografía

Artículo de Erika Lust

\section{Conclusiones}

Tras el análisis de los tres cortos pornográficos seleccionados, propios de la compañía Lust Films, por un lado, encuentro que el principio fundamental de estas producciones está en un trabajo impecable en cuanto a la fotografía y la estética que se conjuga con la narrativa. Esto se encuentra en línea con lo que Erika Lust ha planteado como pornografía para mujeres, al resaltar que los elementos estilísticos, aunado a la historia, juegan un papel crucial para las mujeres como consumidoras de pornografía. Por otro lado, quedan al margen otros elementos, como el uso de los planos, puesto que se observó cómo se continúa recurriendo a planos como el money shot, el cual ha sido referente propio de la pornografía tradicional.

Asimismo, como he discutido, las corporalidades representadas en estas producciones responden a las de un cuerpo hegemónico esculpido por los imaginarios que han reproducido los discursos de las instituciones sociales. Por lo que no se retrata una amplitud de cuerpos con diversas cualidades y (dis)funcionalidades. De este modo, se vislumbra que la escogencia de cuáles cuerpos son retratados y cuáles son excluidos, no es inadvertida. Esto responde a la misma determinación sobre cuáles son los cuerpos que tienen permitido desear y ser deseados, bajo los parámetros de lo social y moralmente establecido por la norma.

Cabe recalcar, a su vez, la constante reiteración visual y narrativa del modelo androcéntrico de sexualidad, con lo cual se demuestra que, a pesar del posicionamiento político en Porno para mujeres (2008), no se materializa aquella búsqueda por distanciarse de elementos que han codificado la representación de la sexualidad a través del lente. Con ello, quedan invisibilizadas una pluralidad de sexualidades no inscritas en este único modelo que, en conjunto con la homogeneidad de las representaciones corporales expuestas en los tres cortos pornográficos analizados, constituyen un cuerpo pornográfico normado y definido; destinado a un cuerpo social establecido.

Ante estos vacíos presentes en las producciones que se posicionan como ajenas y disconformes a la pornografía tradicional, algunas alternativas han apuntado hacia la construcción de un cuerpo pornográfico desde la reapropiación, es decir, desde el agenciamiento individual. La autorepresentación - aunado al exponencial uso del Internet y la creación de plataformas alternas y colectivas - permite que sea retratada la mirada y la experiencia desde la subjetividad, puesto que son los mismos sujetos quienes establecen sus límites y el cómo se desplazan en los mismos. Así, lo que se entiende por censura y obscenidad es cambiante y plural, puesto que responderá a la subjetividad de quien agencia. De forma que la propuesta para generar una ruptura con los modelos corporales y de sexualidad androcéntrica se dirige hacia la autogestión del cuerpo pornográfico.

ESCENA. Revista de las artes, 2020, Vol. 80, Núm. 1 (julio-diciembre), pp. 205-222 


\section{Referencias}

Arcand, B. (1993). El Jaguar y el Oso Hormiguero. Antropología de la pornografia. Argentina: Ediciones Nueva Visión SAIC.

Bonte, A. (18 de septiembre de 2018). Olympe de G, réalisatrice "au service de la représentation du sexe". RTL Journal. Recuperado de https://www.rtl.fr/girls/identites/ olympe-de-g-realisatrice-au-service-de-la-representation-du-sexe-7794818171

Bourdieu, P. (1979). La distinción. Criterio y bases sociales del gusto. Madrid: Taurus.

Corner, N. (25 de mayo de 2018). 'It was my calling': Porn star and avowed feminist defends her career choice - and insists getting paid to 'enjoy sex, shoot on location and eat food' is Empowering. Daily Mail. Recuperado de https://www. dailymail. co.uk/femail/article-5763059/Feminist-porn-star-says-dream-career-calling.html

Echavarren, R. (2009). Porno y post porno. Montevideo: HUM.

Giménez, F. (2015). Pospornografías. Ciudad de México: La Cifra Editorial.

Guerrero, M. (2014). ¿Supera la Pospornografía el heteropatriarcado? (Tesis para optar por el título de Socióloga con mención en Ciencias Políticas). Pontificia Universidad Católica del Ecuador.

Kristeva, J. (1988). Poderes de la perversión: ensayo sobre Louis F. Céline. Ciudad de México: Catálogos Editora.

Lissardi, E. (2013). La pasión erótica: del sátiro griego a la pornografía en Internet. Buenos Aires: Paidós.

Llopis, M. (2010). El postporno era eso. Barcelona: Melusina

Lust, E. (2008). Porno para mujeres. Barcelona: Melusina.

Lust, E. (Productora) y Lust, E. (Directora). (2016). Horney Beasts. [Cortometraje]. España: Lust Films.

Lust, E. (Productora) y Olympe de G. (Directora). (2016). The Bitchhiker. [Cortometraje]. España: Lust Films.

Lust, E. (Productora) y Pappel, P. (Directora). (2016). Female Ejaculation. [Cortometraje]. España: Lust Films.

Maines, R. (2001). La tecnología del orgasmo. Debate feminista, 12, 166-219.

Mulvey, L. (1999). Visual Pleasure and Narrative Cinema. En Leo Braudy y Marshall Cohen (Eds.), Film Theory and Criticism: Introductory Reading (pp. 833-844). Nueva York: Oxford UP. 
Derivas representacionales del cuerpo pornográfico en la cinematografía

Peralta, J. (2017). Reseña sobre Usina posporno. Mora, 23(1), 185-190.

Pineda, A. (2005). Tengo, tengo, tengo... tú no tienes nada' o de los peligros de ciertas 'prácticas subversivas. Quaderns de Filologia-Estudis Literaris, 9, 185-197.

Preciado, P. (24 de abril de 2012). Historia de una palabra: queer. Parole de Queer. [Página web]. Recuperado de http://paroledequeer.blogspot.com/p/beatriz-preciado. html

Romera, L. (2016). El uso del money shot en el cine pornográfico de Erika Lust. Ponencia presentada en I Congreso de jóvenes investigadorxs con perspectiva de género, Instituto de Estudios de Género, Universidad Carlos III de Madrid. 